\title{
Prime Example Ingress \\ Reframing the Pervasive Game Design Framework (PGDF)
}

\author{
Heinrich Söbke ${ }^{1}$, Jannicke Baalsrud Hauge ${ }^{2,3}$, loana A. Stefan ${ }^{4}$ \\ ${ }^{1}$ Bauhaus-Institute for Infrastructure Solutions (b.is), Bauhaus-Universität Weimar, \\ Germany, heinrich.soebke@uni-weimar.de \\ ${ }^{2}$ Bremer Institut für Produktion und Logistik an der Universität Bremen, Germany, \\ baa@biba.uni-bremen.de \\ ${ }^{3}$ Kungliga Tekniska Högskolan, Sweden, jmbh@kth.se \\ ${ }^{4}$ ATS, Romania, ioana.stanescu@ats.com.ro
}

\begin{abstract}
The growing availability of mobile communication infrastructure over the last decade has contributed significantly to the maturity of Pervasive Gaming. The massive success of games such as Ingress and Pokémon Go made pervasive gaming a viable option for transforming learning. By its adaptability to location and context, pervasive technology is a valuable support for the design of engaging learning experiences. Despite profound examples of pervasive gaming as learning tool, there is still a lack of reliable methodologies to construct purposeful pervasive learning experiences. The Pervasive Game Design Framework (PGDF) is intended to fill this gap. In this article, we present the PGDF using the example of Ingress. Ingress is a prominent pervasive game, as it has received huge attention since its appearance in 2012. A large community of players and third-party-tool suppliers has created a rich set of experiences since then. In this research, we examine Ingress according to PGDF's categories based on a survey among long-term Ingress players ( $N=133$ ). Founded on this analysis we identify three main benefits for Ingress players. Furthermore, we discuss the consequences of these findings on the PGDF. Summarizing, this work strengthens the applicability of the $P G D F$, in order to enable the construction of enriched pervasive learning experiences.
\end{abstract}

Keywords: context-aware gaming, pervasive game design framework, Ingress, player motivation, digital educational game, pervasive game

\section{Introduction}

Digital Educational Games (DEGs) are often used to fill in the gap between theory and practice. Games and gamified lessons are usually perceived as more engaging than traditional classes [1]]. However, DEGs are criticised for paying more attention to achieving the learning objective than to motivation and engagement [2]]. This often leads to students feeling less immersed and, consequently, the potential learning outcome is affected negatively as well [3], [[4]. There are different reasons for this: designing games with a good game-play and immerse game players in a realistic setting, while also encouraging replay-ability, is challenging. Employing games in education requires the consideration of the variables that influence learning and those of the learning theories that need to be incorporated into the game design practices. It is also necessary to be able to tailor games for specific learning activities [[5]]. In addition to the game concept and the design challenges, the implementation is challenging, since the games do not only need customisations according to the specific learning goals, but also for fitting the needs of different groups. From Entertainment Games (EGs) we know that pervasive games have the required ability to immerse players and 
research has identified that contextually-relevant information provided by mobile devices can play an important role in facilitating learning [[6]].

Pervasive games are not precisely defined in the literature. A broad definition is given by Montola: "a game that has one or more salient features that expand the contractual magic circle of play socially, spatially or temporally" [[7]]. Based on this definition, different subclasses can be identified, such as urban games (uses the city as play field), or location-based mobile games (focussing on the device used for playing) etc. [[8], [9]]. The popularity of pervasive games, such as Ingress, Pokémon Go and Shadow Cities [10], [[12], has created a cultural shift, making context-aware and AR (Augmented Reality) genres mainstream gaming platforms [[11]]. Games have begun to consume GPS (Global Positioning System) and GIS (Geographic Information System) data from services such as Google, generating new businesses [[13],[14],[[15]. They can also be seen as "platforms" [[16],[17],[[18] "that merge existing electronic media + the Internet +location-based technologies (or locative media) $+A R$ (Augmented Reality) technologies in a new mode of digital composite imaging, data association and socially maintained data exchange and communication." ([18] referred to by [16]]). These games engage people of different ages and have created their own communities that span at international level. Studies have shown that there is an interface between game playing activities and urban life [19],[20],[21]], that Ingress connects to disruptive behaviour [22]], as well as that it can be used in an educational context. In-line with Sheng [23]], this paper intends to analyse in more detail what the players find motivating and engaging in pervasive games, as well as their playing behaviour, in order to use this gained knowledge to refine the Pervasive Game Design Framework (PGDF) and enable the construction of enhanced pervasive learning experiences.

This paper builds upon the outcomes of two workshops organised at ICEC 2015 and 2016 [24], [25]] and aims to investigate the lesson learnt from Ingress to consolidate the dimensions of the PGDF that can be used to guide the design of DEGs based on experiences collected from EGs. The first version of the PGDF has been constructed based on the feedback collected from the ICEC 2015 workshop and it integrated seven dimensions (Pervasive Context, Pedagogical Objectives, Assessment Metrics, Difficulty Level (ranging from casual to challenging), User Skills, Social Interaction, and Elements of Fun) that have been identified as essential when designing engaging context-aware games. The discussions carried out on the PGDF dimensions during the ICEC 2016 workshop have revealed that further investigations are required to strengthen the proposed approach.

The article is structured as followed: in section 2 the methodical approach is described. The following section 3 introduces the pervasive game Ingress with its basic game mechanics and notable manifestations of emergent game play. Thereafter the results of the survey are presented. In section 5 the PGDF is aligned and refined with these findings. Section 6 concludes with a summary and an outlook.

\section{Methodology}

The main reason for investigating the motivation of Ingress players is the possible transfer of the design traits of this successful pervasive game to educational gaming contexts. The PGDF has been designed within the BEACONING project [26]] in order to support the design of immersive educational games, as well as the construction of gamified learning paths. For carrying out the research, we have used an action based research approach.

A questionnaire was used as an explorative tool to collect insights into the motivations to play Ingress. The questionnaire comprised 76 items categorized in seven groups. The last six groups have been built according to a specific research item.

1. Demographic items

2. Are there dominant player type characteristics (given by Bartle's taxonomy)?

3. What are the most attractive actions and achievements?

4. Is Ingress play integrated into daily routine, which would be considered as a prerequisite for the observed long-term engagement?

5. How do players describe their playing-style?

6. What starts and what ends a playing session?

7. What is the general opinion of players on their playing style? 
The design of the questionnaire was based on the knowledge about Ingress contributed by three at least level 8 players of Ingress (Level 8 was the highest possible level, when Ingress was introduced). As a foundation for exploring motivational aspects, we used Bartle's taxonomy [27]].

Each of the question blocks comprises a free-text field to give players the opportunity to provide additional feedback. Participants used this to explain their choices and add further details. This additional information is referenced in section 4, where the results of the questionnaire's research items are presented. Except for the free text field, the other questions were statements to which responders had to assign their grade of agreement on a five-point Likert scale.

\section{Insights into the Ingress Game}

Ingress is one of the first augmented reality games receiving common popularity that has incorporated GPS localization to the game play. Players are to reach physical locations called Portals, where the main resource of the game, the Exotic Matter (XM), is generated. All game actions are carried out by consuming XM. On the other hand, almost each of these actions (cf. list below) is rewarded with Action Points (AP) and items.

At the beginning of the game, players need to choose between two factions: The Resistance that aims to fight against the forces attempting to use the XM to enslave humanity; and The Enlightened whose purpose is to benefit from the power of the XM to evolve mankind to a higher level. This choice at the beginning is a significant trigger for fostering competition and identification during the game.

Each level of the game provides access to a set of objects that the player can use. The maximum game level is 16, while the maximum level for game objects is 8 . Starting with level 9, the storage capacity for XM is increased. For each game activity, the players receive AP, which are accumulated and directly determine a player's level (up to level 8 - higher levels require additionally badges $($ Medals $)$ ). The following list shows a selection of possible activities:

- Hack a Portal. This is the main type of action a player can carry out. It delivers a random number of game items (e.g. Resonators or XMP Bursters). These game items are required to perform other activities. Additionally, a player obtains hundred APs if he hacks a Portal owned by the enemy faction.

- $\quad$ Capturing a portal using a Resonator. A maximum of eight Resonators can be deployed to a Portal. A Resonator is characterized by its level (from 1 to 8). The level of a Resonator determines its resistance against attacks of the other faction. Further, the level of a Portal is given by the level of its Resonators. The level of a Portal defines for its part the level of released items during a hack, i.e. only a level 8 Portal is able to produce a level $8 X M P$ Burster.

- $\quad$ Attack a portal using XMP Bursters. XMP Bursters allow players to destroy Resonators. If all eight Resonators have been destroyed, the Portal is neutral and can be captured again. Destruction of a Portal destroys potentially attached Links and Control Fields (cf. below). Such chained destructions are rewarded with extra amounts of APs.

- $\quad$ Upgrading an ally Portal using Resonators of a higher level than the existing ones.

- Recharging a Portal using the player's XM. The energy level of deployed Resonators drops continuously over time or is reduced by attacks of the other faction. Recharging increases the energy level again.

- $\quad$ Linking Portals by using Portal Keys that are unique for each Portal.

- Create Control Fields by forming triangles out of Links.

- $\quad$ Missions are a kind of Ingress-guided tour to a group of Portals. The player is supplied with additional information and optionally has to answer questions related to the Portals. Missions are player-created content. Their successful accomplishment is awarded with badges.

- Glyph Hack. It is a memorization mini-game and it requires players to memorize the order of the symbols that are displayed on the screen and trace them out within a given amount of time. The number of Glyphs that are displayed and the time allocated to reproduce them depend on the game level

From the view of a faction, it is the main purpose of the game to conquer as many Portals as possible (see 0, left) and to form Control Fields as large as possible in order to gain Mind Units 


\section{pag. 42}

$(M U)$. The $M U s$ represent the population in a Control Field that it is created. There is a global and a local score for the number of MUs owned by each faction. Local competition is supported by Cell Cycles: for a defined region, statistics of MU ownership are aggregated over cycles of 175 hours. At the end of such a period, the faction with most $M U s$ wins (see 0, right). Additionally, specific game mechanics give special meaning to collaborative play. For example, the level of a Portal can be increased to the maximum only by a group of players. A level 8 Portal requires eight level 8 Resonators by eight different players of the same faction.
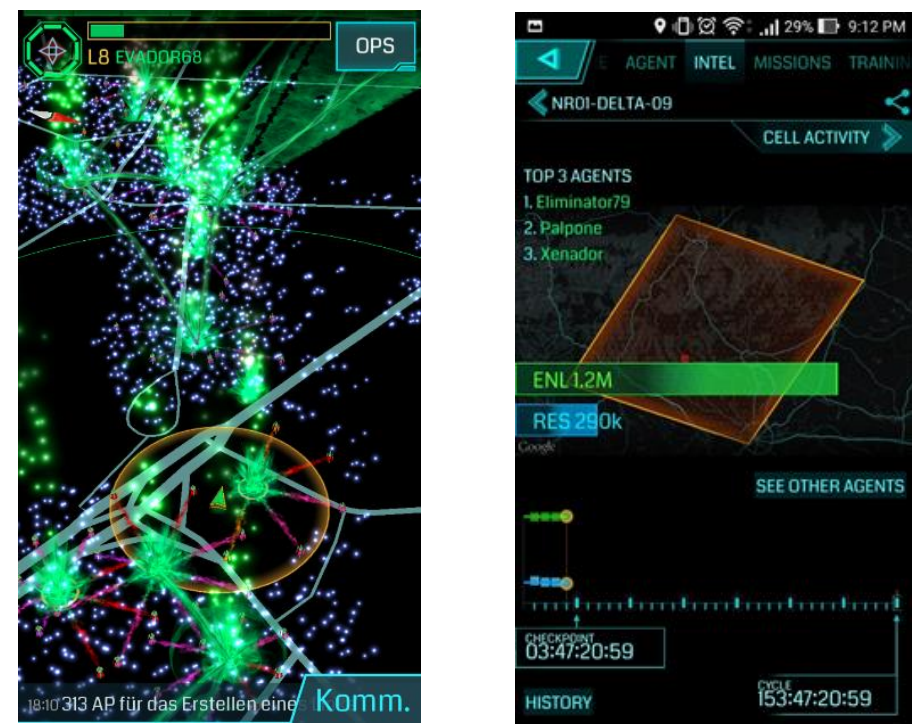

Figure 1 Ingress screenshots: Left: main screen showing Portals (vertical emissions), XM (spots around Portals) Links (green lines in the upper left) and a Control Field (upper right); Right: status screen of a Cell Cycle as a regional competition between the factions

Having casually observed the release of Ingress in 2013 and noticed print articles of Ingress game play (e.g. [28]]), mainly two observations underlined the specific nature of this game: its outdoor playground and the sociability it induces between players. Digging deeper, these observations have been confirmed. For example, a survey of a non-representative sample of altogether 1572 Ingress players from 2013 was carried out in the initial phase of Ingress [29]]. It found that $91 \%$ of respondents were male. The grade of interaction between players is seen as "unusual" as $74 \%$ of players "had met fellow players" and $29 \%$ even have made new friends. Further, the game has increased the daily physical effort: $93 \%$ of players reported that their walking activities were upped by Ingress. The study could not identify any attribute, which can be used to distinguish between the players of both factions. Another effect of the game is the increased use of Google+. These results are widely confirmed by a further non-scientific study in 2015 [30]], aggregating the answers of about 1250 players. The percentage of male players here was $71 \%$. Among the reasons to play Ingress were entertainment (86\%), exploring new places (72\%), exercising $(59 \%)$, having fun to destroy the work of the other faction (57\%), being part of a team with a common goal (55\%), making new friends (54\%) and feeling responsible to "protect" a particular location (36\%). A major motivation was "being destructive", which is mirrored in 0 , too: Tearing down portals is here the second most liked aspect of Ingress. In general, 0, gives an overview of the popularity of Ingress game play traits as found in [30]. 


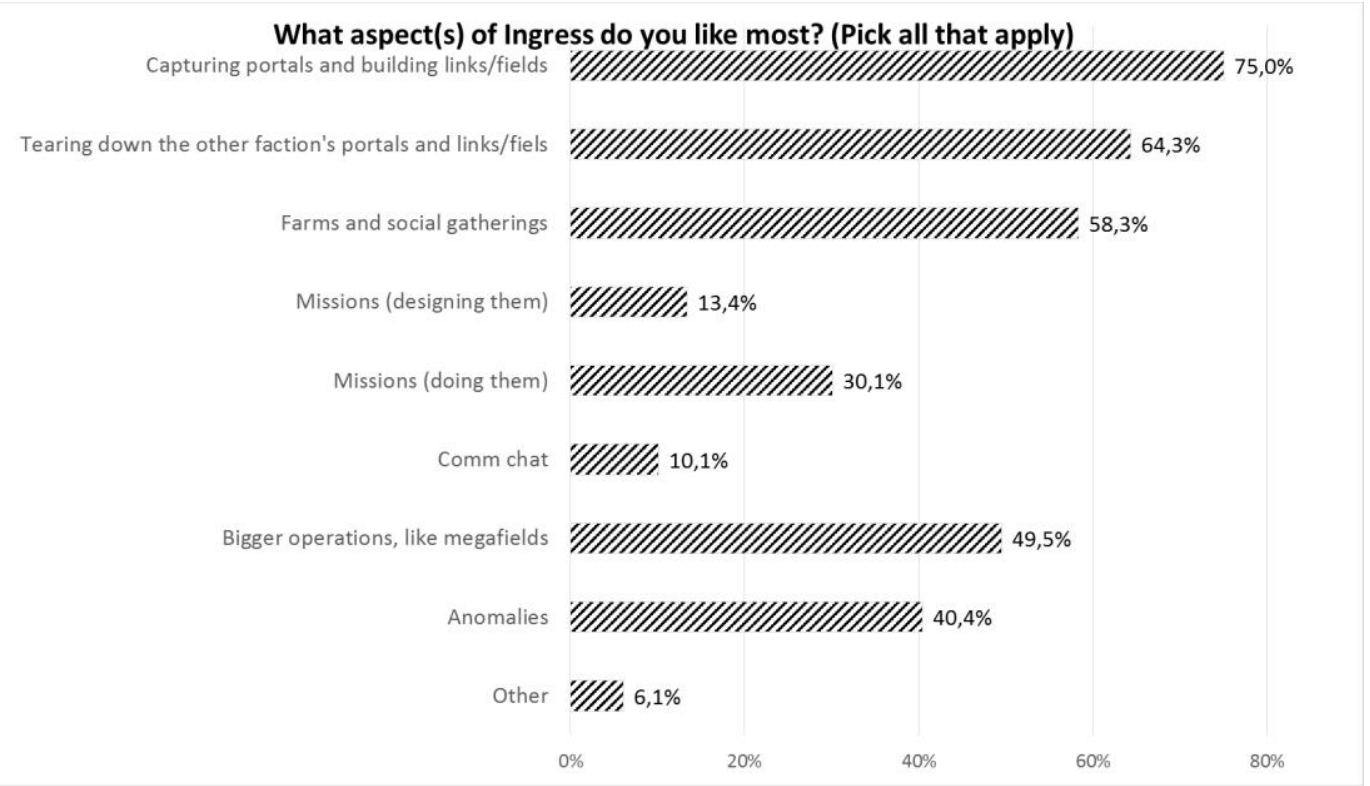

Figure 2 Ingress' aspects and their popularity (Numbers: Percentage of approval, Source: [30]])

Besides these more obvious Ingress aspects, there are further phenomena mostly resulting from emergent game play. In the following some of the most important traits are described.

Ingress Field Art. Field Art is an impressive emergent game play of Ingress. Created Control Fields result in graphical figures on the map. If both factions collaborate, these figures can be of two colours (see 0). This type of art requires a lot skills and efforts: combination of Portals to a motive, working out linking plans and finding participating players (and preventing the non-participating from interfering) are only a few. After having planned such a so-called "X-Faction-Event", the actual work of capturing the portals and linking them is done usually during one evening. The progress can be observed on an online map ("Ingress Intel Map" [31]]). So called "time lapses" visualize these processes (e.g. [32]]). Further manifestations of remarkable creativity and joint effort of Field Art are a Santa Claus figure [33]] and a collection of outstanding examples [34]].

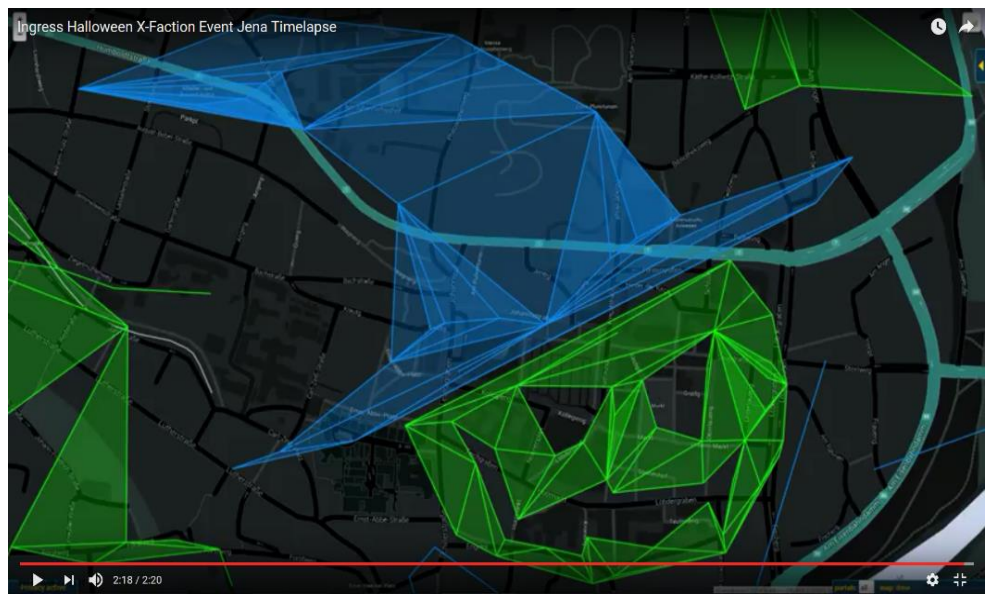

Figure 3 Ingress Field Art example - the result of a temporary collaboration of both factions [32]

Global Planning. Whereas Field Art mostly is done on a regional level, there is also the phenomenon of Giant Fields. These Control Fields span countries or even continents. Their predominant purpose is capturing a large portion of $M U s$, which is a measure for the competition between factions. As the game requires presence at the Portals to conquer them, world-wide collaboration of players is necessary. This enormous organizational effort and cooperation is often document in so called Field Reports on Google+. Examples are the Largest European field [35], the Operation Blue Diamond, a giant field in Sri Lanka [36] and Ingress World of Records, a special website for extraordinary achievements in Ingress [37]. 
Self-defined goals. Field Art is an example for a self-chosen goal in the game. A well-designed game frames the gameplay by a set of game objects and rules. Players exploit this space of possibilities, which is called Emergence [38], [39] or emergent gameplay. As a consequence, there are various opportunities for self-defined goals, self-defined game play and self-expression of players. One example is the achievement of a first level 8 all women portal which was established emblematically at a physical monument in Melbourne, Australia, dedicated to women in medicine ([40], cited in [16]).

Transmedia Usage. Ingress game play not only consist of operating the smartphone app, but includes the utilization of many other media and communication channels. For example, there are web portals, Youtube channels (e.g. to present timelapses of Field Art processes [32]) and Twitter accounts. As Niantic Labs, the developer of Ingress, is a Google spin-off, Google+ is a frequented communication channel within the Ingress community. Ingress Intel Map [31], a web portal offering Ingress related maps has been extended by third party-scripts. The most popular is the IITC-script [41], which allows creating link plans, tracking players, etc. These are further examples for activities of emergent gameplay. Summing up, Ingress is one of those games, which has built a huge community and where actually many game related actions take place outside of the game app.

\section{Results of the survey}

\subsection{Demographics}

The questionnaire was distributed via postings in Ingress user groups and communities mainly populated by German players on Feb. $24^{\text {th }} 2017$. Within three days after posting, 161 participants started the questionnaire, 133 completed it $(\mathrm{N}=133)$. Table 1 shows the distribution of players' age groups. $37 \%$ of participants belong to the age group of 35-45 years, $22 \%$ are older than 45 years. So together, almost $60 \%$ are older than 35 years. Nearly $80 \%$ of participants are male. The average participant in this survey is male and around 40 years old. These findings are in accordance with those reported in [29] and [30].

Table 1. Age of players

\begin{tabular}{l|r}
\hline Age group & Percentage \\
\hline$<\mathbf{1 8}$ & $2 \%$ \\
\hline $\mathbf{1 8}-\mathbf{2 4}$ & $10 \%$ \\
\hline $\mathbf{2 5}-\mathbf{3 5}$ & $29 \%$ \\
\hline $\mathbf{3 5}-\mathbf{4 5}$ & $37 \%$ \\
\hline$>\mathbf{4 5}$ & $22 \%$ \\
\hline
\end{tabular}

\subsection{Experience and level of engagement}

$34 \%$ of the answering players started playing Ingress in 2013 - the year, when Ingress was released officially. The number of indicated game entries decreased straight to 2016, where $16 \%$ had their first encounter with Ingress. The average Ingress level is 14.4. 67 participants have reached the maximum level of 16, the reported minimum level is 8 (four participants). As the level depends on accumulated APs and number and grade of received medals, it can be assumed that some of them would qualify even for higher levels, if those would be established. Our own experiences illustrate the enormous effort which is required to reach these levels: two or three month of continuing, almost daily playing without the support of high level players is a rough estimation of time required to become a level 8 player. Dedicated and strategic approaches can reduce this span a lot (e.g. to less than a day [42]] or two weeks [43]]). However, the reached levels let assume a long-term engagement of participants in Ingress. This assumption is further backed by answers to a question about the current engagement level: $80 \%$ of participants call themselves regular players, further $16 \%$ play occasionally and other $3 \%$ have Ingress still installed on their devices. Another indicator for activity and engagement is the reported weekly time of playing: 30\% estimate their current play-time as 3 to 6 hours a week. An effort of 6-10 hours per week is spent by a quarter (25\%) of players. Another quarter plays more than 10 hours weekly. As a rule of thumb, it seems to be reasonable that players of this study's sample play roughly one hour per day. 


\subsection{Player preferences and motivations}

Ingress' game mechanics seem to address a wide range of motivational aspects. Amongst other activities, players can socialize, they can build up structures and destroy the work of the other faction, they can strive to achieve badges and they are invited to explore new places. In order to get an overview about major motivational elements involved in Ingress game play, we employed Bartle's taxonomy of player types [27]]. The original test to classify a player's preferences according to this taxonomy [44]] contains 30 questions. As the taxonomy and the test were designed to classify players of Multi-User-Dungeons (MUDs), these questions refer in part to MUD-specific game-play and would have been not operable for Ingress players. For this reason, a set of 26 items was created. They ask for the approval to a statement on a five-point Likert scale. Not all of these items describe exclusively only one of Bartle's four main player types (Achiever, Explorer, Socializer and Killer). For example, the item "I like to complete missions." can be typical for both, an Achiever (because a completed mission can be seen as an achievement) and an Explorer (because the mission may lead to new places and new knowledge, when questions have to be answered). Therefore, each item has been rated for its type specific components by three experts. Their ratings have been averaged to calculate an item's contribution to each of the types of Bartle's taxonomy. These contributions have been added component by component and averaged. The results in Table 2 show that Explorer and Socializer are the most dominant motivation components. Achiever and Killer components are less important. However, the differences are within a comparatively small range of 0.4 points. So, there seems not to be a strongly dominating motivation. This is from the perspective of designing a widely accepted game a perfect outcome: all major motivational components are addressed apparently by Ingress.

Table 2. Results for motivational components according to Bartle's taxonomy

\begin{tabular}{r|r|r}
\hline Type component & Mean Value & \multicolumn{1}{|c}{ Deviation } \\
\hline Explorer & 3.72 & 1.07 \\
\hline Socializer & 3.68 & 1.18 \\
\hline Achiever & 3.42 & 1.22 \\
\hline Killer & 3.33 & 1.20 \\
\hline
\end{tabular}

\subsection{Player preferences: actions and achievements}

Participants were asked in how far they like specific actions and achievements in Ingress. The question is similar to the question illustrated in 0 [30]]. However, it comprises a larger choice of game (inter-)actions. Each of them had to be rated on a five-point Likert scale. 0 shows the results ordered by approval grade. The most preferred characteristic of playing Ingress is "being outdoors" with a mean value of 4.3 and the lowest standard deviation of 0.75 . The standard deviation was included in the graphic as a measure of homogeneity of the responses. For example, the activities "(e) creating most complex multilayer-fields" and "(f) caring for the portals of a group" both show a mean value of 3.5, but (e) is characterized by a higher standard deviation (1.37) (see 0). 
(b) having detected new spots in my local environment

(c) common activities with my friends

(d) Medals

(e) creating most complex multilayer-fields

(f) caring for the portals of a group

(g) Statistics

(h) organizing local INGRESS groups

(i) any kind of action which improves my statistics

(j) planning and being part of field art

(k) having learned glyphs

(I) Missions

Z Mean

Deviation

(m) being owner of portals
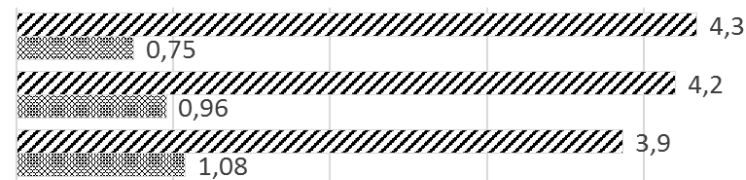

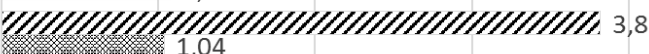

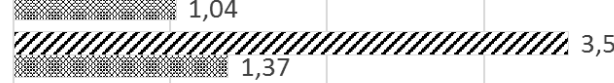

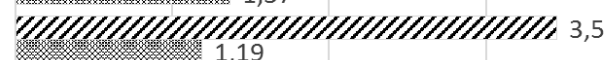

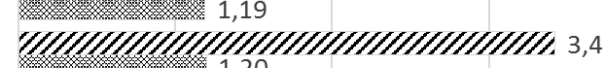

WNUNININ 1,33

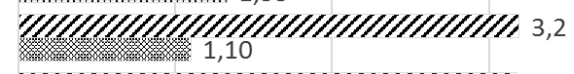

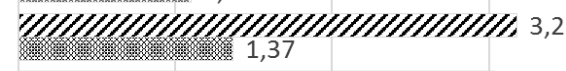

WII/

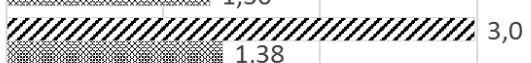

\%

Figure 4 Player preference: actions and achievements (Five-point Likert)

The second most-preferred game result is increased knowledge about the local environment, followed by a social outcome, the common activities with friends. Only the fourth most-important item is an in-game achievement: medals seem to be the best motivating formal game element.

Besides the given selection of actions and achievements in the above question, participants were invited to share their not included personal preferences of actions or achievements. Fifty-three additional textual responses to this question have been given. These answers have been coded and assigned to categories. 0 shows the results. So called Ingress Anomalies, events officially organized by Niantic Labs, are the most named feature. They take place in cities all over the world and comprise some hours of common gameplay and a social gathering at the end. Further, Ingress was referred to as an opportunity to perform healthy common outdoor activities with the whole family. Some players mentioned that Ingress helps to strengthen characteristic traits like willpower and discipline. Another often-reported characteristic of Ingress is connecting people of a great diversity (Rows 3 and 8 of 0 ). Often it leads to inspiring travelling activities to other places, too.

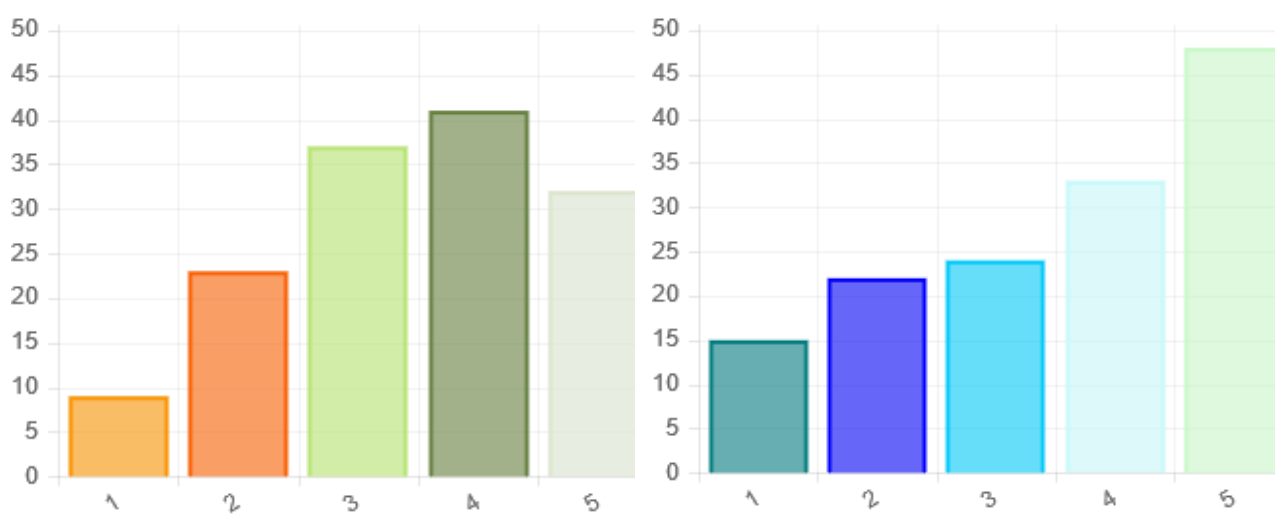

Figure 5 Distribution of votes for $(f)$ caring for portals (left) and (e) creating multilayer fields (right) 
Table 3 Categorization of achievements and actions in textual responses

\begin{tabular}{|c|c|c|c|}
\hline & Category/Code & $\begin{array}{l}\text { number of } \\
\text { occurences }\end{array}$ & Description / Example quote \\
\hline 1 & Ingress Anomalies & 10 & $\begin{array}{l}\text { Common Ingress playing events at certain location, sup- } \\
\text { ported by Niantic Labs }\end{array}$ \\
\hline 2 & Socializing & 9 & "meeting new people", "the community is just awesome" \\
\hline 3 & $\begin{array}{l}\text { New diverse acquaint- } \\
\text { ances }\end{array}$ & 9 & $\begin{array}{l}\text { "Meet people of other age, social group or profession which } \\
\text { I would have never met without Ingress." }\end{array}$ \\
\hline 4 & Identification & 8 & $\begin{array}{l}\text { being part of a bigger construct (i.e. the faction or local } \\
\text { groups) }\end{array}$ \\
\hline 5 & $\begin{array}{l}\text { Resonance, power and } \\
\text { status }\end{array}$ & 7 & $\begin{array}{l}\text { One's own actions are recognized by others: "to rule the } \\
\text { area and prevent the other fraction from ruling" }\end{array}$ \\
\hline 6 & $\begin{array}{l}\text { Competition between } \\
\text { factions }\end{array}$ & 7 & $\begin{array}{l}\text { "Building farms for our team and destroying those of the } \\
\text { others, guardian hunting, destroying home / work portals of } \\
\text { the other team" }\end{array}$ \\
\hline 7 & $\begin{array}{l}\text { Travelling and new } \\
\text { places }\end{array}$ & 6 & $\begin{array}{l}\text { "meet unknown players in unknown cities and play with } \\
\text { them" }\end{array}$ \\
\hline 8 & $\begin{array}{l}\text { New acquaintances in } \\
\text { general }\end{array}$ & 4 & "found a lot new friends" \\
\hline 9 & Fitness \& wellness & 4 & $\begin{array}{l}\text { Playing Ingress as an outdoor activity requires a lot of walk- } \\
\text { ing and makes players go outside, which promotes physical } \\
\text { and mental well-being. }\end{array}$ \\
\hline 10 & $\begin{array}{l}\text { Observation and over- } \\
\text { view }\end{array}$ & 3 & $\begin{array}{l}\text { Players can study movements on an overview map and ob- } \\
\text { serve the activities of other players. }\end{array}$ \\
\hline 11 & Specific achievements & 3 & $\begin{array}{l}\text { "I love the Mindcontroller badge", "Deploying and hunting } \\
\text { long time portals"," Quick thinking challenges, thinking } \\
\text { outside the box. [...] scheduled faction meet-ups." }\end{array}$ \\
\hline 12 & $\begin{array}{l}\text { Large field collabora- } \\
\text { tion }\end{array}$ & 3 & $\begin{array}{l}\text { Creating large fields spanning multiple countries requires } \\
\text { the collaboration of players on an international level. }\end{array}$ \\
\hline 13 & $\begin{array}{l}\text { Socializing outside of } \\
\text { Ingress }\end{array}$ & 2 & $\begin{array}{l}\text { Acquaintances from Ingress meet outside the game for other } \\
\text { common spare time activities. }\end{array}$ \\
\hline 14 & Dedication & 2 & $\begin{array}{l}\text { "being crazy enough to take a multi-hour journey to get } \\
\text { some keys (especially in a group of similar crazy people)", } \\
\text { "as a reason to get up at } 5 \text { am, or driving } 300 \mathrm{~km} \text { for it" }\end{array}$ \\
\hline 15 & $\begin{array}{l}\text { Willpower \& disci- } \\
\text { pline }\end{array}$ & 2 & Successful Ingress play requires willpower and discipline. \\
\hline 16 & Healthy family activity & 2 & Ingress can be played outdoors as a common family activity. \\
\hline 17 & Cell Cycles & 1 & $\begin{array}{l}\text { Cell Cycles provide a measure to determine the more suc- } \\
\text { cessful faction, i.e. they are a feature to spur competition. }\end{array}$ \\
\hline 18 & $\begin{array}{l}\text { Enjoyment / Escapism } \\
\text { / Pleasure }\end{array}$ & 1 & "Have time for my own on an Ingress journey." \\
\hline 19 & Attitudes & 1 & $\begin{array}{l}\text { Continuing competition requires sound attitudes towards the } \\
\text { players of the other faction, e.g. respect and tolerance. }\end{array}$ \\
\hline 20 & Suspense & 1 & $\begin{array}{l}\text { If two groups compete strategically with each other in a cell, } \\
\text { there is always suspense if plans work as intended or are in- } \\
\text { terfered. }\end{array}$ \\
\hline 21 & Banner missions & 1 & Multiple badge mission, which combine to a picture. \\
\hline 22 & Satisfaction & 1 & $\begin{array}{l}\text { "The satisfaction when a plan works out and half a dozen } \\
\text { agents act in sync and the fields go up in minimal time." }\end{array}$ \\
\hline
\end{tabular}

\subsection{Habitual integration into daily life}

The survey shows that Ingress players spent on a regular base a considerable amount of time with playing activities (e.g. in sec. 0 one hour per day was estimated). This extent of time cannot be spent by chance, but has to be reached by a habitual integration of game play into the routines of daily life. Such a long-term engagement is a characteristic which is desirable for formal learning contexts as well. For this reason, a deeper analysis of mechanisms leading to this habitual integration can be seen as beneficial for possible applications in serious contexts.

0 shows a choice of possibilities for intermingling of Ingress play and real-life - given in a survey question - and their approval rates based on a five-point Likert scale. A mean value $(\overline{\mathrm{x}})$ of 3.8 shows that many players care for portals at home or at work, i.e. they recharge it at regular intervals. Furthermore, important portals regularly are periodically checked, if they are still owned 
pag. 48

by their faction $(\bar{x}=3.7)$. Commuting activities are used for farming, i.e. for collecting items by hacking portals $(\overline{\mathrm{x}}=3.7)$. There is a high approval $(\overline{\mathrm{x}}=3.6)$ for the statement that there are regular dedicated Ingress walks, e.g., dog walks or accompanying one's children to school. The thesis that Ingress play would be always a separate activity seems not to be true $(\overline{\mathrm{x}}=2.6)$. Notification e-mails - which are sent e.g. in the case an owned portal is under attack - play a less dominant role $(\overline{\mathrm{x}}=2.8)$. This can be valued as a hint that players tend to have an acting role and do not play in a reactive manner.

The survey results are reinforced by the text responses: Ingress play seems to be integrated into daily routines, or augments them, e.g. "I often take a detour on my daily routes to pass along more portals" or "The morning newspaper was replaced by my G+Stream and the HangOuts Backlog". Further game play has become a routine as it is indicated by a daily activity of "gather keys, modules and weapons and distribute them to other agents". Another comment goes even further: "you can't play Ingress like other games...it's more like a fusion between my life and Ingress". Both the survey and text responses show that playing Ingress is integrated into players' daily activities and has become habitual: at home, during commuting, at work during work and during leisure hours.

(a) I care for a portal when I am at work or at home

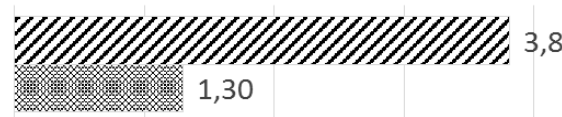

(b) I do some farming work when I am commuting

(c) I check the status of the portals and fields of my faction in regular intervals.
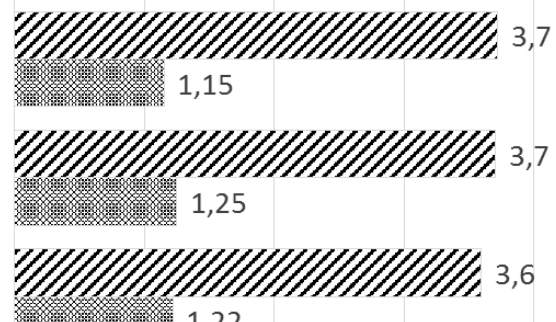

(d) I play INGRESS on regular dedicated walks

(e) I attend regular meetings of INGRESS groups

(f) My notification e-mails are switched on

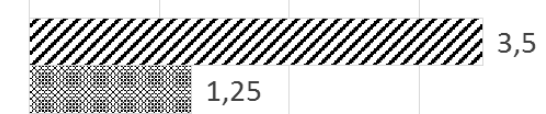
(g) It is always a separated activity "Mean Deviation

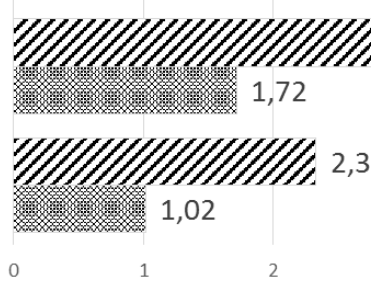

Figure 6 Integration of playing activities into daily routines

\subsection{Self-description of playing style}

The personal opinion of players about their play provides some valuable insights: to know if playing feels like work, if a dedicated goal is always aimed at or if it is more like a social process would help to derive design goals for serious pervasive games. Therefore, players were asked to indicate their agreement with certain playing style facets. 0 shows the results. Striking is the strong embedding in a social environment, i.e. the common play in groups and their organization via social networks. Playing Ingress seems to be attractive as a kind of team sport in informal groups $(\overline{\mathrm{x}}=3.9)$. Furthermore, most players show a systematic approach to Ingress $(\bar{x}=3.4)$ : they try to reach a goal, but at the same time they allow themselves to pursue a gameful attitude, i.e. not to act compulsively and impelled $(\bar{x}=3.0)$. However, some players admit that playing Ingress can feel like work. These results are mirrored by a comment "It's only a game! We love this game; we hate this game."

Not that important to players is a status-oriented playing-style and documenting the results $(\bar{x}=2.3)$. The hypothesis that players were only active when the game was a hype has to be rejected for this group of long-term players $(\overline{\mathrm{x}}=1.7)$.

The comment field for this question revealed more detailed roles and further approaches to play Ingress. There are builder types, who try to implement structures. Other players work on their own, or give special attention to the efficacy of their play. Specialists try to receive specific badges, e.g. the Guardian Medal, which is issued when a player is the owner of a portal for a defined long period of time. Role players fulfil their tasks in a team, e.g. they farm items for other players. To these activities also belongs administrative work to coordinate multinational teams or building software 
infrastructure tools to assist strategic planning of actions in the game. Others describe their game play as "mildly aggressive, trying to break a long held dominance of the opposing faction in the area by blasting them". Another strategic approach can be read from this comment: "when we get destroyed, we need to rebuild our environment fast to prevent wrong links/fields that cause weak portals". Fairness is an always reoccurring issue in the game. Cheating as a phenomenon has been mentioned multiple times, even as a reason to quit the game.

(a) Strongly embedded in a social environment, I am a part of a group.

(b) Purposeful and dedicated, always striving to reach a goal.

(c) Casual, playing INGRESS when it comes to my mind.

(d) Playing INGRESS can feel like work.

(e) I regularly post my achievements or contribute to field reports

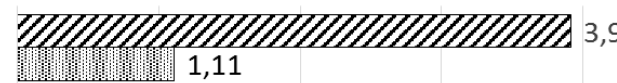

(f) I played it, when it was a hype.

Mean 娄 Deviation

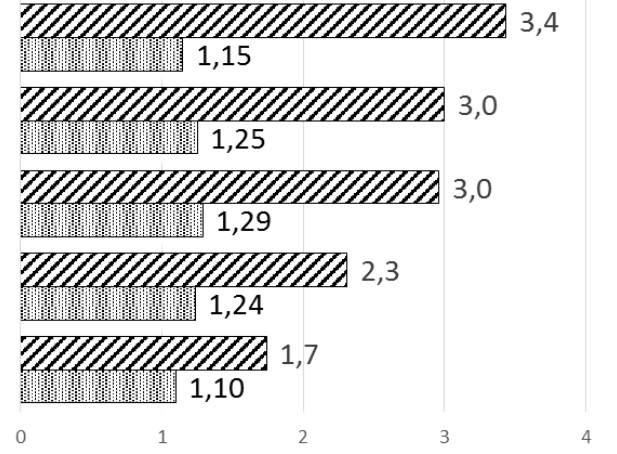

Figure 7 Self-description of playing style

\subsection{Triggers for starting and ending a session}

Actually in serious contexts a game should be seen as a mostly voluntarily activity. For this reason, it is important to know why such an activity is started and ended. Only when the player is occupied by the game it can become effective regarding its serious purpose. In 0 possible triggers for the start of a session are presented. They mirror the main player-named benefits of Ingress. The most dominant trigger is coming to a foreign location $(\overline{\mathrm{x}}=4.2)$. This may be encouraged especially by a specific statistic (Unique Portals Visited). Another explanation is the motivation to learn about the environment using Ingress. The social environment is further an important trigger $(\overline{\mathrm{x}}=4.0)$ : friends ask to team up. The need and pleasure of being outdoors is an additional motivation to start playing Ingress $(\overline{\mathrm{x}}=4.0)$. Vice versa, Ingress is often started as a casual by-product of being outdoors $(\overline{\mathrm{x}}=3.7)$. Gamerelated triggers like damage-mails $(\overline{\mathrm{x}}=2.6)$, recharging portals $(\overline{\mathrm{x}}=3.2)$, and improvement of personal game-statistics $(\overline{\mathrm{x}}=3.2)$ are less effective. In the comments to this question, other game-related triggers have been mentioned sporadically (Cycles and learning Glyphs). Further, a few sessions are started, when the map reveals good opportunities to improve the statistics. Summarizing, personal needs as being outdoors and being in company can be considered as a more effective trigger than in-game requirements. Furthermore, it seems that purposeful long-term strategies are more important than short-term needs and incidents- like losing a portal - in the game. 
(a) coming into a foreign location

(b) friends ask to accompany them

(c) when I need to catch fresh air and go out

(d) farming or preparation of playing sessions

(e) by incidence, when I am outdoors

(f) when I have new ideas for extraordinary fields

(g) when I want to improve my statistics or to achieve badges

(h) when it is time to recharge the resonators

(i) when I get damage mails resp. when I have lost the ownership of a portal

(j) when I see interesting comments in the chat log

$\square$ Mean 图 Deviation
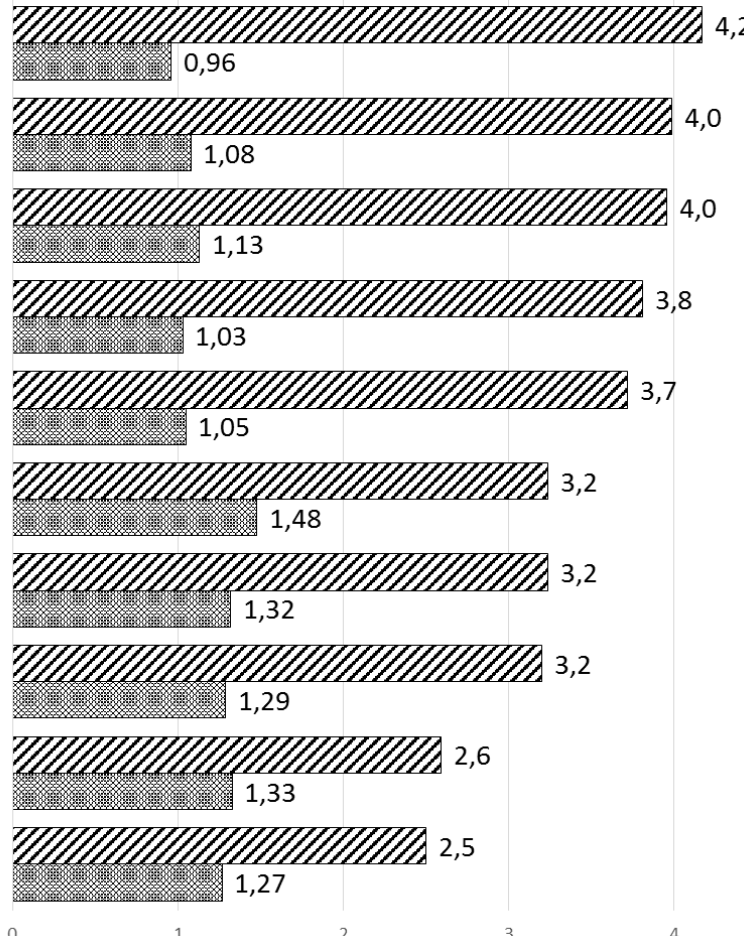

Figure 8 Triggers for starting a game session

(a) other activities required

(b) when I have reached my goals (Recharging, Farming, Fielding, ...)

(c) when I am totally exhausted, head is aching, thumbs are aching ...

(d) no fun anymore

(e) weather conditions

(f) out of ressources: no more battery, no data volume left, ..

(g) my friends are leaving

(h) interference of other faction's players

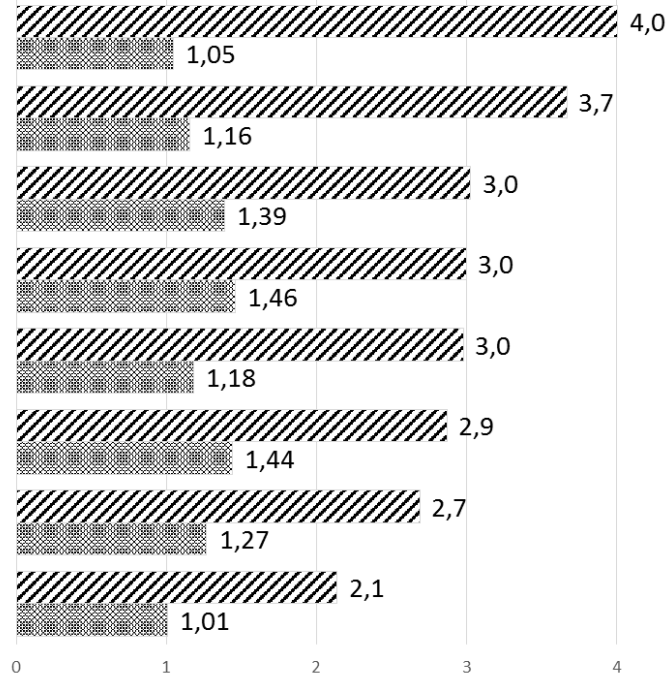

Figure 9 Triggers for ending a game session

The main reason to end a playing session is urgent other activities $(\bar{x}=4.0$, see 0$)$. The second most important reason is that player's goals of the playing session have been reached $(\bar{x}=3.7)$. Together, these reasons point again to the purposeful nature of playing Ingress. Additionally, this thesis is reinforced by potential reasons, which got only lower approval ratings: exhaustion and fatigue $(\overline{\mathrm{x}}=3.0)$, missing fun $(\overline{\mathrm{x}}=3.0)$, weather conditions $(\overline{\mathrm{x}}=3.0)$, depleted technical resources $(\overline{\mathrm{x}}=2.9)$, leaving friends $(\overline{\mathrm{x}}=2.7)$ and interference from opponents $(\overline{\mathrm{x}}=2.1)$. So, it seems that there are a many potential session ending triggers. However, they are each valued less important than having reached in-game goals. Multiple times higher forces like "nuclear strike in progress", "being hit by a bus" or simply "blisters" have been named half-seriously as ending triggers. The main reasons to end the session are the requirements of real life. The incidentally occurrence of non-playing friends was explicitly named as such a requirement. 


\subsection{Players summarizing comments}

The survey asked players to summarize their motivation. $50 \%$ of players replied. In these summarizing comments, the players listed again the three main benefits of Ingress game play: socializing with others, outdoor activities and exploring and learning about the environment. They added further aspects. Identification with their faction or their local group is important. Feedback from one's environment is critical: most activities are seen and noticed by others. This is a result of the game's design notion of two factions. Whenever a player of one faction conquers a portal, a reaction is provoked. Therefore, the player gets a response to their actions, even if it is a response by a personally unknown player. The resulting competition seems to be another important feature. Collaboration is further an appreciated feature of the game play, which takes place across geographies: internationally, nationally, regionally and locally. The need for walking from portal to portal can be seen as a fitness training, which is additionally tracked and visualized in the game statistic Distance Walked. Ingress allows even in moments of idle time, e.g. waiting for the bus or just relaxing at home, casual activities like recharging portals or tidying game items ("For me the best way to relax is to sort my keys, my weapons, etc."). Furthermore, it provides opportunities for complex tasks: So, players can optimize their walking routes in order to maximize their efficacy or they can design Field Art and develop plans and how the resulting strategies can be implemented. Thus, Ingress offers a wide range of playing opportunities and secondary activities around the core game play.

\subsection{Discussion}

The questionnaire reached a relatively homogeneous group of experienced and dedicated Ingress players. They show a picture of a very engaging game, which has become part of their daily life. The main benefits of participating in this game include (1) its demand for outdoor activities, (2) the necessary exploration of the local environment, and (3) the encouragement for social interactions on local, regional or worldwide level. These findings correspond to the analysis of motivational elements according to Bartle's taxonomy, which revealed the slight dominance of Socializer and Explorer components over Killer and Achiever components for this group of long-term Ingress players. The important finding is that all components are quite evenly addressed. This contributes to a high attractiveness of the game as various motivational components contribute to the game experience on an alternating level: destruction of Portals satisfies Killer components, the next day a badge is received, which leads to Achiever-like satisfaction, thereafter it is necessary to explore the location of a new Portal etc. On a more abstract level, it can be assumed that the versatility of addressed motivational components keeps up the motivation in the aggregate. From the perspective of game mechanics, Ingress offers a broad range of possible activities and game actions - which even contributes to the emergence of various roles in a team - and therefore can meet the expectations of various player types. Considering the named main benefits (1-3), the genre of pervasive games seems to benefit enormously from being played outside and the possibility to investigate the local environment. Although, socialization is an important phenomenon in many other games as well, pervasive games encourage meetings with other players through physical encounters at the locations of outdoor-activities, e.g. the portals in Ingress. It is remarkable, that the mentioned personal benefits (outdoor activity, sociability and exploration) prevail the motivation generated by in-game achievements like badges and statistics. However, it has to be assumed that without in-game achievements the game would not work as it is. They can be considered as superficial trigger to play the game, which results on a higher level in the named personal benefits. Additionally, it has to be mentioned, that players seem to be dedicated, but not to be addicted, as many times participants pointed out in comments that they are able to refrain from playing Ingress in the presence of non-playing friends. In this way, they are able to balance the requirements of the game and their real life.

Of course these results bear some limitations. First of all, the distribution of the questionnaire in online communication channels of engaged Ingress groups led probably to a strong selection bias. Thus, mainly those players who are attracted by Ingress and are integrated in a community have been reached. This has to be considered as a limitation to the transfer of findings to all serious pervasive games: such games have to reach a larger portion of the specific target groups like student cohorts. For this reason, there are further investigations necessary: especially former and short-time Ingress players need to be asked for their motives to leave the game.

The findings have shown the capabilities of pervasive games to implement enriched levels of engagement and motivation. Since they integrate easily with daily activities (e.g. commuting; travelling; walking the dog) and social activities, they enable the construction of new experiences that 
pag. 52

are more personal to the player. This blend between the game play and the player's real life facilitates the design of more engaging game mechanics.

\section{Ingress through the lens of the PGDF}

The results of the questionnaire and an analysis of the Ingress game have been used in order to consolidate and in consequence to refine the Pervasive Game Design Framework (PGDF), which was created to set a reference for the design of pervasive educational games. 0 gives an overview of the current components of the PGDF. In this section, the dimensions of the PGDF are discussed based on the results of the survey.

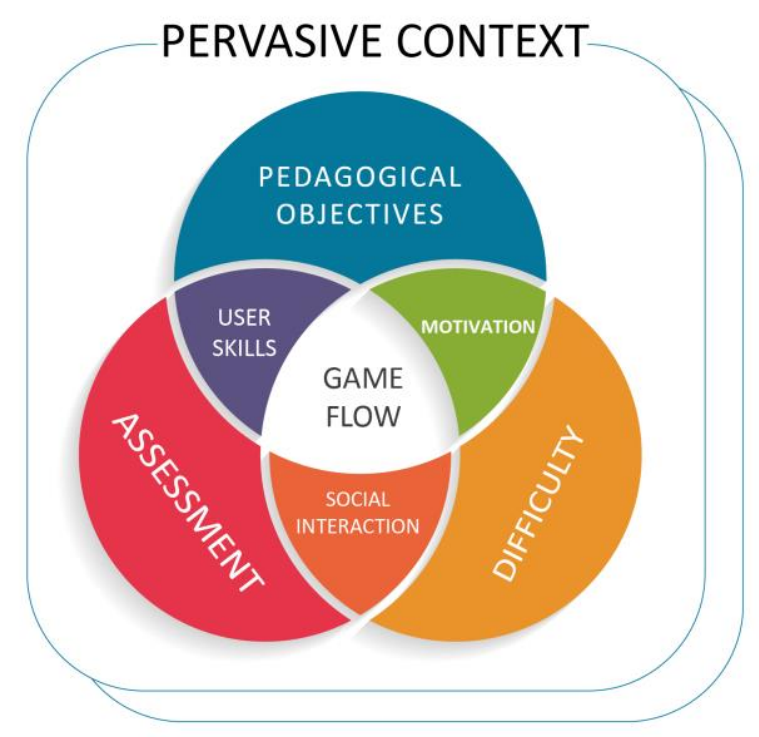

Figure 10 The Pervasive Game Design Framework (PGDF)

\subsection{Pervasive Context}

A major challenge for the design of a DEG is the creation of a level of engagement that is seen in successful EGs (e.g. [45]]). As pervasive games build upon the GPS capabilities of mobile devices and begin to consume more accurate location data, employing context-aware services in DEGs has the capability to strengthen the learning outcome by exploring pervasive contexts. The survey has shown that the pervasive game Ingress has a high capacity to engage players, with an average playing time of one hour per day during lasting long periods of months and years. Therefore, exploring the benefits of pervasive mechanics in educational settings (e.g. the pervasive contexts in Ingress are constructed by overlaying the physical locations with a virtual layer of portals, links and fields) creates the prerequisites for designing more engaging DEGs.

\subsection{Pedagogical Objectives}

DEGs have specific pedagogical objectives that need to be weaved into the game flow, without altering the motivational triggers. It has been extensively argued that EGs can be successfully used for learning (e.g. [46], [[47], [48]]). In the case of Ingress, there have been reported direct instructional usages, too. So, Davis (2016) [49]] has employed the app "as an educational tool to supplement geography classroom instruction in an undergraduate higher-education setting" and points besides advantages in the final test especially to affective impacts on the students. Additionally, there are a lot of potential pedagogical usages. So the game design and the observed community form Ingress to a game, which requires players to develop the so-called $21^{\text {st }}$ century skills like collaboration, communication or teamwork [50]]. Furthermore, Chess [16]] concedes that Ingress "becomes a means of teaching players about their own regional spaces": Defined portals are a kind of statement what is important in a region. For example, missions can be considered as a means of guided tour to 
the most important locations, e.g. historic buildings. Questions like "How can you get most points out of an existing set of portals?" foster modelling and decision making-skills [51]].

The pervasive approach can be extended to integrate pedagogical objectives in certain technical domains. Thus, the game does not stress on the pedagogical metrics, but weaves the learning into the fabric of pervasive game play. An example is Missions: they are itineraries, each passing selected portals. These portals can be open or hidden, i.e. textual hints describe the next portal. To complete a mission, the answer to a simple question can be required - a further opportunity of learning.

\subsection{Assessment Metrics}

For each Ingress player an extensive set of statistical indicators is provided, e.g. Unique Portals Visited and Distance Walked. Almost each type of action is subject to a metric. In summary, the total number of APs, which is one determining factor for the Ingress level, is a measure for the activities. From the player's perspective this addresses the Achiever motivational component. From the perspective of educational assessment, it builds a sound foundation: each implicit (e.g. movement) and explicit action (e.g. hacking a portal) is recorded and counted in statistical indicators. However, metrics in EGs differ from those required in educational settings, although some EG metrics can be explored from a pedagogical point of view like implicit assessing actions in sports or use math formulas to be able to hack a portal.

\subsection{Difficulty Level \& User Skills}

To stimulate learning, the game play should balance players' skills and the game difficulty, in order to provide a level of supportive challenge, which does not bore the player, but does not overstrain it at the same time (Zone of Proximal Development (ZPD) [52]]). The level design of Ingress implements this requirement. The difficulty to reach the next level increases level by level. Furthermore, Ingress provides a rich selection of game interactions the player can choose from. As each of these actions results in $A P \mathrm{~s}$, there is always a metric of progress. It depends on the player to choose tasks with an appropriate difficulty. Examples are Portals that require players to have reached a certain game level to be able to destroy or to protect it. Another example is the creation of fields: they can be created on all geographic levels (from local to worldwide). Local fields are constructible very easily. However, giant fields require collaboration with foreign players, highlighting communication as a key skill that players need to display. As the questionnaire shows, the activity of getting known by persons from other countries is a main motivational element of dedicated Ingress players. Therefore, in this context, the motivational elements and skill development correspond. Additionally, there is a great variety of third party software, which eases mastering a lot of challenges related to Ingress. In this context, the app Portal Calc [53]] helps to calculate the effort of actions. Medal Calculator [54]] is a means of tracking progress according to time periods and My Teams [55]] is even a team management software, which is able to assign tasks to members and supports the planning of different kinds of collaborative events. Such game-extending software can increase the efficiency and efficacy of players' actions. Therefore, it shifts the impact of players to new difficulty levels. One example are those tools, which support the planning and implementation of Field Art.

\subsection{Social Interaction}

The questionnaire showed that the social layer plays a significant role in pervasive games and it creates a deeper involvement for all players. Results have revealed that teaming up with other players is considered a normal activity by most players, with only $2 \%$ of players choosing a solitary approach. Also, $44 \%$ enjoy very much talking with other Ingress players and $66 \%$ enjoy participating in Ingress events. 


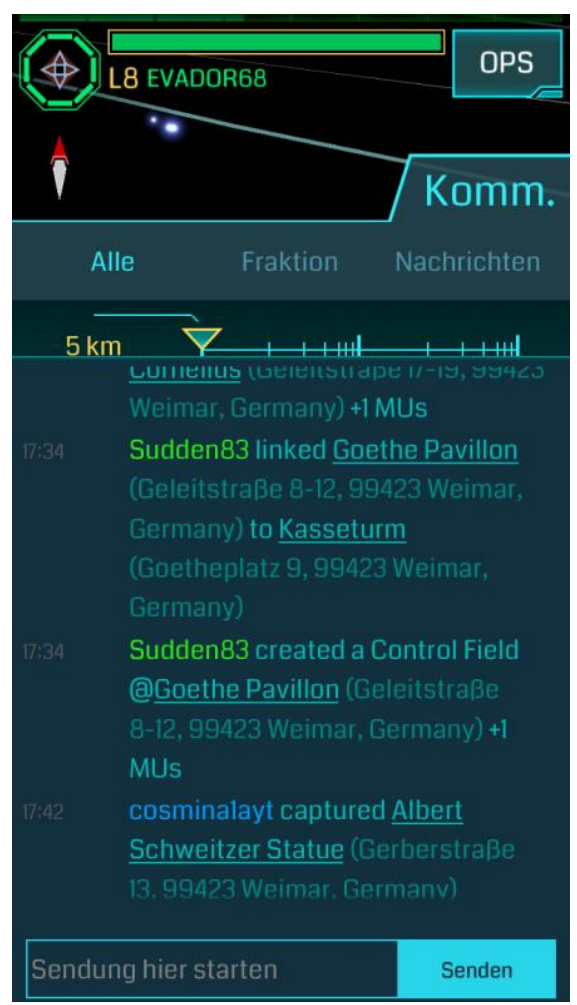

Figure 11 Monitoring and chat tool

There are many Ingress design traits which foster social interactions and can easily be transferred to other pervasive games: Collaboration is required for specific actions (e.g. creation of a level 8 Portal). The mandatory Google \pm and Google-Account leads to community building on Google+ [16]] (Example of a Google+ page of regional group: [56]]). Seamless integrated chat communication is supported by Google Hangouts. The evolution of community-typical procedures is based on these communication channels. An example is given by the hash tag \#FindTheClue on Google+, which describes Ingress related riddles [57]]. The app chat (see 0) is a further example of an easily accessible communication channel [58]]. Furthermore, events like Anomalies [59]] or Mission Days [60]], which the questionnaire identifies as popular activities, lead to interactions. Li et al. [58]] conclude that to "ensure a successful social gaming experience, designers should carefully manage the difficulty for gameplay, provide efficient communication channels for players, and cultivate the player-friendly culture within the game to ensure players' continuous dedication."

\subsection{Motivation}

Following the answers to the survey, we can conclude that there are overarching game benefits which are founded on in-game motivational elements contributed by game mechanics like APs and Medals. Those three main benefits, which motivate Ingress players, have been already mentioned: outdoor activities, sociability and exploration. They are based on motivational components, which have been analysed as comparatively even distributed according to Bartle's taxonomy. In consequence, a pervasive educational game benefits if the design takes into account those three major design goals and tries to reach them based on game-mechanics which address all motivational components (here: Achiever, Explorer, Socializer, and Killer). Such a design provides an exciting, versatile set of challenges, which keep the players playing the game and contribute thereby to those three dominant goals.

\subsection{Summary}

The outcome of the questionnaire has validated the relevance of the proposed dimensions for designing pervasive educational contexts. The results mirror those categories and provide evidence on their relevance for the design process. Remarkably, they led to the extension of the fun dimension to include motivation. The answers of the questionnaire highlighted the fact that the strength of entertainment games is driving motivation and that the factors that are important are competences, 
autonomy and social inclusiveness, which is fully in line with [61]],[[62]. The results also revealed that in Ingress these three components are perfectly balanced in such a way that they drive the motivation. Based on the analysis of the game components, we have integrated this in the PGDF framework.

\section{Conclusion \& future work}

Constructing an engaging game is the key challenge that lies at the core of game design. This challenge becomes even more complex when designing games for learning, as the focus is on addressing specific pedagogical objectives while constructing an engaging game play. This research comprised the development and distribution of a questionnaire among Ingress players, with the purpose of identifying the engagement factors within a popular pervasive game and support the adoption of motivational elements within educational settings. The outcome of the questionnaire has been used to strengthen and adjust the dimensions of the PGDF that aims to serve as a reference point for educational games designers. However, in order to foster this take-up, more specific guidelines (like those provided for the ATMSG [63]] and LM-GM [64]] frameworks) need to be developed. This will be a part of future work within the BEACONING project. The provided insights into the playership of Ingress identified clear design goals for educational pervasive games from the perspective of perceived player benefits, as there are outdoor activities, sociability and exploration. These goals should be implemented by a preferably versatile set of game-mechanics, which addresses a broad range of motivational elements. Interestingly, these goals correspond to the cited definition of the term Pervasive Game by Montola [7]]: Spatial and social dimensions of the game contribute to the long lasting temporal extension of the game play. When constructing educational pervasive contexts, collaboration, communication, and teamwork have been identified as skills that can be targeted under pedagogical objectives in pervasive games. Furthermore, subject specific pedagogical objectives can be adopted for subjects such as math, logistics, sports, art, or history, exploring for example the textual hints that describe a new portal. Each action in both educational and entertainment games is subject to a metric. However, when constructing educational games, assessment metrics are linked to specific pedagogical objectives. Existing metrics in EGs usually require customization for education, but in some cases they can be explored as such. The research has highlighted the importance of balancing user skills and the difficulty level of the game, in order to strengthen the motivation and avoid frustration. Social interaction has been identified as a key element when constructing pervasive context. Social mechanics can be explored in the design process to engage users and support the achievement of specific pedagogical objectives.

To further substantiate the research, the questionnaire will be - after having included the findings of this study and probably a more pervasive game-specific player type categorization than Bartle's taxonomy can be - applied with casual players of Ingress, in order to identify whether the findings are generally relevant or they apply to active game players. In a further step these findings have to be implemented in PGDF guidelines in order to enable their usage without impacting their efficacy. This refers to the identification of appropriate learning objectives as well as to the design of fitting educational scenarios.

\section{Acknowledgement}

The work presented herein is partially funded under the Horizon 2020 Framework Program of the European Union, BEACONING - Grant Agreement 68676 and by Unitatea Executiva pentru Finantarea Invatamantului Superior, a Cercetarii, Dezvoltarii si Inovarii (UEFISCDI) in Romania, Contract no. 19/ 2014 (DESiG).

\section{References}

[1] Baek, Y., Touati, A. (2017). Exploring how individual traits influence enjoyment in a mobile learning game. Comput. Human Behav. 69, 347-357, http://dx.doi.org/10.1016/j.chb.2016.12.053

[2] Azadegan A., Baalsrud Hauge J., Harteveld C., Bellotti F., Berta R., Bidarra R., Riedel J. and Stanescu I.A. (2013). The move beyond edutainment: Have we learned our lessons from the 
entertainment industry?. In proceeding of: First International Conference on Games and Learning Alliance (GALA 2013), At Paris, France, Volume: 1. 10/2013

[3] Harteveld, C. (2011) .Triadic game design: Balancing reality, meaning and play. London, UK: Springer. https://doi.org/10.1007/978-1-84996-157-8

[4] Kiili, K., de Freitas, S., Arnab, S., Lainema, T. (2012). The Design Principles for Flow Experience in Educational Games, Procedia Computer Science, Volume 15, 2012, Pages 78-91, ISSupply Network 1877-0509, http://dx.doi.org/10.1016/j.procs.2012.10.060

[5] Costanza, R., Chichakly, K., Dale, V., Farber, S., Finnigan, D., Grigg, K., Heckbert, S., Kubiszewski, I., Lee, H., Liu, S., Magnuszewski, P., Maynard, S., McDonald, N., Mills, R., Ogilvy, S., Pert, P. L., Renz, J., Wainger, L., Young, M., Ziegler, C. R. (2014). Simulation games that integrate research, entertainment, and learning around ecosystem services, Ecosystem Services, Volume 10, Pages 195-201. http://dx.doi.org/10.1016/j.ecoser.2014.10.001

[6] Guribye, F., Wake, J.D., Wasson, B. (2014). The practical accomplishment of location-based game-play: design and analysis of mobile collaborative gaming. Int. J. Mob. Hum. Comput. Interact. 6, 32-50. https://doi.org/10.4018/ijmhci.2014070103

[7] Montola, M. (2005). Exploring the edge of the magic circle: Defining pervasive games. Proc. DAC. 1966, 16-19.

[8] de Souza e Silva, A., \& Hjorth, L. (2009). Playful Urban Spaces: A Historical Approach to Mobile Games. Simulation \& Gaming, 40(5), 602-625. http://doi.org/10.1177/1046878109333723

[9] Oppermann, L., \& Slussareff, M. (2016). Pervasive Games. In R. Dörner, S. Göbel, M. D. RustKickmeier, M. Masuch, \& K. Zweig (Eds.), Entertainment Computing and Serious Games (pp. 475-520). Springer International Publishing. http://doi.org/10.1007/978-3-319-46152-6_18

[10] Giddingsbile, S. (2016). Pokémon Go as distributed imagination. Mobile Media \& Communication, 5(1). http://doi.org/10.1177/2050157916677866

[11]Lanham, M. (2017). Augmented Reality Game Development. Packt Publishing.

[12] Schuster, S. (2013). Shadow Cities closing down October 7. Retrieved 27 December 2016, from https://www.engadget.com/2013/09/20/shadow-cities-closing-down-october-7/

[13] Hodson, H. (2012a). Google's Ingress game is a gold mine for augmented reality. New Scientist, 216(2893), 19. https://doi.org/10.1016/S0262-4079(12)63058-9

[14] Hodson, H. (2012b). Why Google's Ingress game is a data gold mine. Retrieved 28 December 2016, from https://www.newscientist.com/article/mg21628936-200-why-googles-Ingressgame-is-a-data-gold-mine/

[15] Buettel, J. C., \& Brook, B. W. (2016). Egress! How technophilia can reinforce biophilia to improve ecological restoration. Restoration Ecology, 24(6), 843-847. http://doi.org/10.1111/rec.12387

[16] Chess, S. (2014). Augmented regionalism: Ingress as geomediated gaming narrative. Information, Communication and Society, 17(9), 1105-1117. http://doi.org/10.1080/1369118X.2014.881903

[17] Kasapakis, V., \& Gavalas, D. (2015). Pervasive gaming: Status, trends and design principles. Journal of Network and Computer Applications, 55, 213-236. http://doi.org/http://dx.doi.org/10.1016/j.jnca.2015.05.009

[18] Lapenta, F. (2011). Geomedia: on location-based media, the changing status of collective image production and the emergence of social navigation systems. Visual Studies, 26(1), 14-24. http://doi.org/10.1080/1472586X.2011.548485

[19] Fragoso, S., \& Reis, B. M. S. (2016). Ludic Re-enchantment and the Power of Locative Games: A Case Study of the Game Ingress. In J. Abdelnour-Nocera, M. Strano, C. Ess, M. der Velden, $\&$ H. Hrachovec (Eds.), Culture, Technology, Communication. Common World, Different Futures: 10th IFIP WG 13.8 International Conference, CaTaC 2016, London, UK, June 15-17, 2016, Revised Selected Papers (pp. 131-148). Cham: Springer International Publishing. http://doi.org/10.1007/978-3-319-50109-3_9

[20] Shirai, A., Kose, Y., Minobe, K., \& Kimura, T. (2015). Gamification and Construction of Virtual Field Museum by Using Augmented Reality Game 'Ingress'. Proceedings of the 2015 Virtual Reality International Conference, 4:1--4:4. http://doi.org/10.1145/2806173.2806182

[21] Majorek, M., \& Du Vall, M. (2015). Ingress: An Example of a New Dimension in Entertainment. Games and Culture, 11, 1-23. http://doi.org/10.1177/1555412015575833

[22] Hunzaker, M. A. (2016). Intent or Misinterpretation? Disruptive Behaviors within Ingress. North Carolina State University. 
Söbke H., Baalsrud-Hauge J., Stefan I. A., Prime Example Ingress. Reframing the PGD Framework

[23] Sheng, L. Y. (2013). Modelling learning from Ingress (Google's augmented reality social game). 2013 IEEE 63rd Annual Conference International Council for Education Media (ICEM). http://doi.org/10.1109/CICEM.2013.6820152

[24] Baalsrud Hauge, J. M., Lim, T., Louchart, S., Stanescu, I. A., Ma, M., \& Marsh, T. (2015). Game Mechanics Supporting Pervasive Learning and Experience in Games, Serious Games, and Interactive \& Social Media. In K. Chorianopoulos, M. Divitini, J. Baalsrud Hauge, L. Jaccheri, \& R. Malaka (Eds.), Entertainment Computing - ICEC 2015: 14th International Conference, ICEC 2015, Trondheim, Norway, September 29 - October 2, 2015, Proceedings (pp. 560-565). Cham: Springer International Publishing. http://doi.org/10.1007/978-3-319-24589-8_57

[25] Baalsrud Hauge, J. M., Stanescu, I. A., Stefan, A. (2016). Constructing and Experimenting Pervasive, Gamified Learning, Entertainment Computing - ICEC 2016: 15th International Conference, ICEC 2016, Wien, Austria.

[26] Beaconing Consortium (led by Coventry University). (2017). Beaconing - Breaking Educational Barriers with Contextualized Pervasive and Gameful Learning. Retrieved May 12, 2017, from http://beaconing.eu/

[27] Bartle, R. A. (1996). Hearts, Clubs, Diamonds, Spades: Players Who Suit MUDs. Journal of MUD Research, 1(1), 19.

[28] Porteck, S. (2013). Vive la Résistance! Ingress: Googles Augmented-Reality-Spiel. c’t Mag. für Comput. 82-85.

[29] spacespacedruid. (2013). The Demographics of Ingress. Retrieved 28 December 2016, from https://spacedruiddotcom.wordpress.com/2013/01/23/the-demographics-of-ingress/

[30] Winegarner, B. (2015.) The 2015 Ingress demographic survey. Retrieved 6 May 2017, from https://medium.com/@ beth_winegarner/the-2015-ingress-demographic-survey-6e7181790069.

[31] Niantic Inc. (2016). Intel Map. Retrieved 28 December 2016, from https://www.ingress.com/intel.

[32] HonsW. (2014). Ingress Halloween X-Faction Event Jena Timelapse. Retrieved 27 December 2016, from https://www.youtube.com/watch?v=KCUyEXALIrE

[33] Anweiler, M. (2014). Ho ho ho! It looks like Santa Claus is running to you! Retrieved 28 December 2016, from https://plus.google.com/114983544873853837818/posts/dmHST8J9Jqg

[34]Ellen, V. (2016). The best \#Ingress Field art. Retrieved 28 December 2016, from https://plus.google.com/collection/kpH2fB

[35] Ingress Resistance Freiburg. (2014). Die Resistance Freiburg im Breisgau thriumphiert. Retrieved $28 \quad$ December $2016, \quad$ from https://plus.google.com/103805943542403432692/posts/Wi9oXNadm3g

[36] Gaveen Prabhasara. (2013). Operation Blue Diamond. Retrieved 28 December 2016, from https://plus.google.com/+Ingress/posts/J43mhSHwMWX

[37] Ingress World of Records. (2016). Retrieved 28 December 2016, from https://plus.google.com/communities/117782624970818286386

[38] Juul, J.. (2002). The Open and the Closed: Game of emergence and games of progression. In: Mäyrä, F. (ed.) Computer Game and Digital Cultures Conference Proceedings. pp. 323-329. Tampere University Press., Tampere

[39] Dormans, J. (2012). Engineering Emergence: Applied Theory for Game Design, (Doctoral dissertation, Universiteit van Amsterdam).

[40] Ingress (2013). 5 New Mods Revealed | INGRESS REPORT - EP11, Retrieved 12 February 2017 from https://www.youtube.com/watch?v=9_YanhWyG8Y.

[41] Breunig, S., \& Atkins, J. (2016). Ingress Intel Total Conversion. Retrieved 28 December 2016, from https://iitc.me/

[42] Heltidsluffare (2013). Ingress: Level 1 to 8 in 13,5 hours, Retrieved 11. November 2016 from https://www.youtube.com/watch?v=gev2TqFS22c.

[43] Beltzung, L. (2013). Erweiterte Selbsterfahrung mit Google Ingress: in 2 Wochen zum Level 8 Spieler, Retrieved 11 November 2016 from https://motherboard.vice.com/de/article/die-ingresswelt-ist-ein-dorf.

[44] Andreasen, E., \& Downey, B. (1996). The Bartle Test of Gamer Psychology. Retrieved 5 December 2016, from http://matthewbarr.co.uk/bartle/

[45] Egenfeldt-Nielsen, S. (2006). Overview of research on the educational use of video games, Retrieved 3 June 2012 from http://www.itu.dk/people/sen/papers/game-overview.pdf.

[46] Gee, J.P. (2008). What Video Games Have to Teach Us About Learning and Literacy. Palgrave Macmillan, New York.

[47] Squire, K.R. (2011). Video Games and Learning: Teaching and Participatory Culture in the Digital Age. Teachers College Press, New York. 
[48] Wouters, P., van Nimwegen, C., van Oostendorp, H., van der Spek, E.D. (2013). A Meta-Analysis of the Cognitive and Motivational Effects of Serious Games. J. Educ. Psychol.. , vol. 105, no. 2, pp. 249-268, http://doi.org/10.1037/a0031311

[49] Davis, M. (2016). Ingress in Geography: Portals to Academic Success? Journal of Geography, 116(2), 89-97. http://doi.org/10.1080/00221341.2016.1227356

[50] Trilling, B. and Fadel, C. (2012). 21st century skills: Learning for life in our times. John Wiley $\&$ Sons.

[51] Shetty, P. (2013). How to make 4 control fields in Ingress - Efficient Linking. Retrieved 28 December 2016, from https://www.youtube.com/watch?v=rkugS47h0j8

[52] Vygotsky, L.S. (1978). Mind in society: The development of higher psychological processes. Harvard University Press., Cambridge, MA.

[53]Braintrapp. (2016). Portal Calc for Ingress. Google Play Store. Retrieved from https://play.google.com/store/apps/details?id=com.gombosdev.Ingressportalcalc\&hl=de

[54]Emsy, \& Effizienz. (2014). Ingress Medal Calculator. Google Play Store. Retrieved from https://play.google.com/store/apps/details?id=com.emsy.ocrmedals\&hl=de

[55] Frīdenvalds, D. (2016). My Teams (for Ingress). Google Play Store. Retrieved from https://play.google.com/store/apps/details?id=com.df.Ingresslv

[56] Ingress Thüringen - Wo Frosch und Schlumpf sich gute Nacht sagen. (2016). Retrieved 28 December 2016, from https://plus.google.com/communities/103562843419268919558/stream/c3cf8ef1-a94d-4c28-96a8-660766913b93

[57] Google+ (2017). \#FindTheClue, Retrieved 9 May 2017 from https://plus.google.com/s/\%23FindTheKlue/top.

[58] Li, R., Liu, S., Liu, Y., Tu, H.-Y., \& Yang, X. (n.d.). A Probe into Ingress and Its Social Interaction: Augmented Reality's Influence on Mobile Game Community Design. Retrieved 28 December 2016, from http://vince-li.com/pdf/Ingress/paper.pdf

[59] Niantic Inc. (2016). Ingress Live Events. Retrieved 28 December 2016, from https://www.ingress.com/events

[60] Google+ (2017). \#IngressMissionDay, Retrieved 9 May 2017 from https://plus.google.com/s/\%23IngressMissionDay/top.

[61] Rigby, S. \& Ryan, R. M. (2011). Glued To Games - How Video Games Draw Us In and Hold Us Spellbound. Santa Barbara, California: ABC-CLIO, LLC.

[62] Koster, R. (2005). A Theory of Fun for Game Design. Scottsdale, Arizona: Paraglyph Press.

[63] Carvalho, M.B., Bellotti, F., Berta, R., De Gloria, A., Sedano, C.I., Baalsrud Hauge, J., Hu, J., Rauterberg, M. (2015). An activity theory-based model for serious games analysis and-conceptual design. Comput. Educ. 87, C (September 2015), 166-181, https://doi.org/10.1016/j.compedu.2015.03.023

[64]Lim, T., Louchart, S., Suttie, N., Baalsrud Hauge, J., Stanescu, I.A., Ortiz, I.M., Moreno-Ger, P., Bellotti, F., Carvalho, M.B., Earp, J., Ott, M., Arnab, S., Berta, R. (2014). Narrative Serious Game Mechanics (NSGM) - Insights into the Narrative-Pedagogical Mechanism. In: Göbel S., Wiemeyer J. (eds) Games for Training, Education, Health and Sports. GameDays 2014. Lecture Notes in Computer Science, vol 8395. Springer, Cham https://doi.org/10.1007/978-3-31905972-3_4 